\title{
A Consciousness-raising Grammar Teaching Approach Based on Grammar Teaching Dilemmas
}

\author{
Xiaqing Liu ${ }^{1,2} \mathrm{a}^{*}$ and Yuting Dou ${ }^{1, \mathrm{~b}}$ \\ ${ }^{1}$ College of Foreign Studies, Shandong Technology and Business University, Yantai, Shandong, \\ China 264000 \\ ${ }^{2}$ School of Economics and Management, Nanjing University of Aeronautics and Astronautics, \\ Nanjing, Jiangsu, China 210016 \\ aliuxiaqing111@163.com, b332853225@qq.com
}

\begin{abstract}
Keywords: Grammar teaching; Consciousness-raising (CR); Grammar teaching dilemma; Explicit; Implicit; Focus on form
\end{abstract}

\begin{abstract}
Grammar teaching has been a heated topic in the field of foreign language learning and teaching. The research of grammar teaching lies between the continuum of a series of grammar teaching dilemmas. This paper first reviews the pendulum movements of researches and their related grammar teaching approaches and methods, discusses three dilemmas involved with grammar teaching, and draws conclusions regarding to how to address with dilemmas. In view of the current situation in second language teaching, a consciousness-raising grammar teaching approach is discussed from the aspects of its concepts, characteristics, patterns and application in foreign language teaching.
\end{abstract}

\section{Introduction}

Grammar has held and continues to hold a central place in language teaching (Ellis, 2006: 101). Grammar has been an indispensable part of language teaching, which plays a crucial role in some foreign language teaching methods such as grammar-translation teaching, and takes a minor or even negligible proportion in such teaching methods as communicative methods (Heng, 2007). Major issues related to grammar teaching are whether language teaching should be focus-on-forms or focus-on-form (Hadley, 1993; Long, 1988, 1998), whether grammar should be taught explicitly or implicitly (Schmidt, 1993; Ellis, 2005), and whether grammar rules are obtained deductively or inductively (Fortune, 1992; Brown, 1994), which are discussed below in detail. Research finds itself somewhere in the continuum of those extremes and the research trends move and swing like a pendulum.

Until 1970s, grammar instruction had been emphasized in foreign language teaching before the rise of communicative language teaching (CLT) (Heng, 2007). Since then, traditional grammar teaching has become less popular and grammar courses were cancelled by most of schools and universities. Under the pressure of evaluation system and curriculum state, communicative teaching method is not as ideal as what had been expected. Since 1990s, new approaches for grammar teaching have been studied (Lin \& Jia, 2015). Consciousness-raising grammar teaching may be one of approaches to split the differences between traditional grammar teaching and CLT. On the one hand, learners can involve themselves in the types of task completion which will enhance learners' motivation. On the other hand, learners can formulate the grammar rules with the help of consciousness raising which may make up for the drawback of inaccuracy of communicative approach.

\section{Literature Review}

There are mainly three dilemmas in grammar teaching, namely, focus on meaning vs. focus-on-forms, explicit grammar teaching vs. implicit grammar teaching, and deductive grammar teaching vs. inductive grammar teaching respectively.

Dilemma 1: 'Focus on Meaning' or 'Focus-on-fomrs'. A review of language teaching and learning can give a blue-print of how research results influence the grammar teaching pendulum to swing. With 
the recognition of Skinner's Stimulus Response (S-R) psychology in the 1940s and 1950s, it was thought that language should be taught by "extensive drill and practice without recourse to rationalistic explanation" (Hadley, 1993: 46). In opposition to this, Noam Chomsky argued that behaviorist theory could not explain why children are able to create language they have never heard (Hadley, 1993). Chomsky's innate language acquisition holds the idea that language is a system and humans are born with the ability to learn language (Shrum \& Eileen, 2010). The innate language view gave birth to Krashen's Five Hypotheses (Krashen, 2003), which distinguish the concepts of acquisition and learning. His natural order hypothesis describes that second language can be learned in a natural and predictable order. Krashen's Hypotheses dominated foreign language teaching in the latter half of the 20th century, which contribute to the zero-grammar teaching approach (Heng, 2007).

The two extremes are also illustrated as 'focus on meaning' and 'focus on forms' (Long, 1988: 115). 'Focus on meaning' refers to raising learners' awareness to linguistic elements as they appear incidentally in lessons, and derives from the assumption that second language can be acquired in the same way as the first language from natural input, interaction and communication (Long, 1988). However, 'focus on forms' prefers to teach discrete grammar points separate from the context. Based on these two extremes, a third option 'focus on form' is put forward to deal with the L2 as an object, including grammar, but within an otherwise communicative classroom (Long, 1998:179).

Dilemma 2: Explicit or Implicit. The second dilemma is between explicit grammar teaching and implicit grammar teaching. According to Ellis (2005), explicit grammar teaching refers to declaring knowledge of grammatical features of L2 in metalanguage to label this knowledge. By contrast, implicit grammar teaching does not illustrate or teach grammar points directly. Interface hypothesis can be used to explain explicit and implicit grammar teaching. There are three positions as following: 'non-interface positon', 'interface positon', and 'weak interface positon' (Ellis 2005: 210). The non-interface positon believes that explicit grammar teaching is transitory and superficial which cannot improve real language competence and cannot be converted to implicit knowledge (Truscott, 1996, 1998). The interface position argues that explicit knowledge will become implicit knowledge with the help of communicative practices (DeKeyser, 1998). The weak interface position points that conscious noticing language forms is an essential part of the language learning and explicit knowledge is an indispensable part of acquisition processes (Schmidt, 1993).

As Lin \& Jia (2015) pointed, the three positions derive various grammar teaching approaches. For instance, the non-interface position supports a zero-grammar approach, such as Natural approach and Total Physical approach. The interface position prefers PPP, namely presentation, practice and production. The weak interface position supports task-based language teaching. The variability of positions and approaches lay foundation for post-method pedagogy.

Dilemma 3: Deductive or Inductive. The third dilemma is between deductive or inductive grammar teaching. As for deductive grammar teaching or grammar rule-driven teaching, grammar rules and concepts are presented first and then the applications are implemented. By contrast, inductive grammar teaching proceeds from particulars or specifics to generalities, so it is also called rule-discovery learning (Fortune, 1992). The deductive approach enjoys a monopoly position in many course books and grammar books (Glaser, 2016). In this approach learners may have less fear of drawing wrong conclusions. The inductive approach involves the learners' participating from the very beginning of examples presentation (Felder \& Henriques, 1995). In other words, grammar rules are illustrated implicitly and learners are expected to conclude or summarize the rules by themselves. Brown (1994) proposes that inductive approach comforts more easily to the concept of interlanguage development.

There are many researches taking a middle ground of this dilemma. For instance, Ellis (2006) states that simple rules may best be taught deductively, while more complex rules may best be taught inductively. A lot of empirical studies show learners achieve better in deductive language lessons, while others prove that inductive way is more effective (Erlam, 2003; Glaser, 2016). 


\section{Rethinking Dilemmas}

The three dilemmas stated above are overlapped with each other. With regard to the first dilemma, grammar is the summary of facts in a language which should be learned and acquired by learners. Utterances full with grammar mistakes cannot achieve the expected communicative effects. Therefore, 'focus on form' is recommended for it covers both the forms of language and their usage in contexts. Secondly, both implicit and explicit knowledge should be developed in grammar teaching. The implicit grammar teaching can be prioritized, while explicit grammar teaching should not be neglected. Finally, deductive and inductive should not be set in the positions against each other. They can be used in different teaching contexts with consideration of learning motivation, teaching requirements and practical situations. There are a variety of grammar teaching approaches which are trying to optimize the effects of grammar input and output, such as processing instruction, interactional feedback, textual enhancement, and task-based approach (Heng, 2007). Among various grammar teaching, PPP, namely, presentation, practice, and production or provision, is the most popular one. The first step is to present a grammatical structure, and then practice in controlled exercises, usually in the forms of pattern drills or blank fillings. At last, learners produce texts in accordance with grammar rules. Most of the grammar textbooks and guidebooks adopt the PPP model. It has limitations but on the hand, it also has its characteristics such as efficiency and directness. On the basis of analyses on three dilemmas of grammar teaching and present grammar situation, a consciousness-raising grammar teaching approach is proposed to provide an approach for grammar teaching.

\section{Consciousness-raising Grammar Teaching Approach}

The Concept of Consciousness. The term of 'grammar consciousness-teaching' refers to a method deliberately make learners come into notice about the formal properties of a language (Rutherford \& Sharwood-Smith, 1985: 274). In this way, learners can be equipped with clear and deep understanding of grammar features, which will further help them develop declarative knowledge of the language. Grammar conciseness-raising, based on cognitive psychology instead of behavioristic psychology, does not return to traditional grammar teaching ( $\mathrm{Lin} \& \mathrm{Jia}, 2015$ ). Conciseness-raising cannot guarantee successful language acquisition, but it is a 'necessary and sufficient condition for language acquisition' (Schmidt, 1993: 210). To some extent, consciousness-raising grammar teaching is a trade-off for grammar teaching dilemmas.

The final aim of consciousness-raising is to raise learners' awareness towards accuracy. Consciousness is one of the prerequisites transferring from input to intake. Learners can compare the information what he or she receives with his or her interlanguage information, which is also called notice gap. In this way, learners will notice the difference and make necessary adjustments to the gap and finally realize accuracy.

Consciousness-raising grammar teaching approach is different from the traditional grammar teaching. Firstly, consciousness-raising grammar teaching focuses on long-term language learning instead of a specific grammar structure. Secondly, learners understand and acquire the features of grammar structures based on their own cognitive competence and their cognitive activities involves the process of notice- hypothesis- verification. Thirdly, consciousness-raising grammar approach puts the grammar structures into context instead of independent grammar points presentation. Finally, consciousness-raising grammar may release the resistance of those who are weary of language learning. In traditional grammar teaching, grammar points are listed as rules just like mathematical formula. In fact, grammar is the rules induced and summarized artificially and it has a lot of diversifications and particular cases. Traditional grammar teaching makes a large number of students scared of language learning, while consciousness-raising can improve such aversion because learners can acquire grammar in a more natural way.

Consciousness-raising in Grammar Instruction. The consciousness-raising can be conducted both deductively and inductively. If the inductive way is applied, it shares the similarity with discovery learning, in which learners may discover the rules by means of observation, inquiry, inferring, and 
prediction, and conclusions can be regarded as being tentative instead of final. To some extent, consciousness-raising is helpful for explicit knowledge and implicit knowledge teaching because learners take control of learning pace by themselves. The implicit consciousness-raising grammar teaching is recommended for the reason that if a learner is unable to integrate grammar features as implicit knowledge, he or she will construct an alternative explicit representation which will be stored separately for further accession (Ellis, 2002). According to Willis and Willis (1996) and Ellis (2002), procedures for implicit conscious-raising grammar teaching can be presented as following.

Step 1: scenario setting: Learners are exposed to an authentic text with specific grammar features. There should be adequate examples to make sure most of learners are able to grasp the features.

Step 2: comprehension questions: Meaning of the text is checked first, and then learners are expected to answer the questions.

Step 3: noticing: learners notice the grammar forms and try to relate the forms with meaning. Target grammar structures can be highlighted or underlined in the text. Isolated sentence structure analysis without context should be avoided.

Step 4: hypothesizing: Grammar consciousness-raising activities can be conducted in groups, pairs or individually. Learners are encouraged to make assumptions and present them in front of group members or whole class.

Step 5: checking hypothesis: Learners check their assumptions with group members or partners, or verify their assumptions with more examples.

Step 6: confirmation: Teachers confirm the assumptions in the way of highlighting the correct assumptions and present them rather than wasting time in rectifying those incorrect ones. Teachers play the role of summarizer and confirmer instead of controller or knowledge provider.

Consciousness-raising Grammar Teaching Practice - Second Conditional. Suppose it's a multi-lingual class and the language learning of students is intermediate level. Their learning motivation for studying English differs with each other. Some of them study for professional title grading, some want to improve English communicative skills, others study for interests in language and one studies to teach her children English. They need to immerse themselves into an English communicative environment. If grammar points are taught directly to them, they will feel bored easily. Contexts where specific grammar points or sentence patterns are used should be shown to them. They can deduce the rules by themselves and they can use the them naturally. As a student in an intermediate-level class, the learners have accumulated lexical words, such as adjectives describing people's looks and charter and personality and have mastered basic communicative skills, and past simple tense. As for the related sentence patterns, they have learned zero conditional which expresses a situation that is always true and the first conditional with the sentence pattern "If + subject + simple present, subject + will + verb" which express real possibilities. They will learn the third conditional in the following week.

At first, teacher should design the acquisition process. Three sentence patterns for second conditional which is used to express the impossible things at present or in the future, as are shown below. It is necessary to remind the students of the difference between first conditional and second conditional and highlight the part forms. The first sentence pattern is discussed in view of lack of space.

"If I were you/ sb./ sth., I would do sth ..."

"If I won £ 5 million, I would...",

"If I could do..., I would..."

Then it comes to the specific instruction practices.

Step 1. Introduction. Review first conditional by interactive question "If it's sunny this Sunday, what will you do?" and tell students what we will be studying about second conditional — three sentence patterns in second conditional.

Step 2. Activity 1: Listening music — "If I were a boy". Hand out the materials and explain that they are required to fill in blanks about the lyrics referring to the bold words. Repeat the video if necessary. If I were a boy, I think How it feels to love a girl

I swear I'd be a better man

Cause I know how it hurts When you lose the one you wanted 
Cause he's taken you for granted And everything you had got destroyed

If I were a boy

Tell everyone it's broken So they think that I was sleeping alone

And make the rules as I go

Cause I know that she'd be faithful Waiting for me to come home (to come home)

Step 3. Check the lyrics answers and ask the question "Why using 'If I were a boy, I would/ could ...' instead of 'If I am a boy, I will..."'? Let students brainstorm and guess the answers. Do not judge the right or wrong at this stage.

Step 4. Show them the rest of the lyrics using different colors to draw their attention as following Fig.1, and they can draw the conclusion easily.

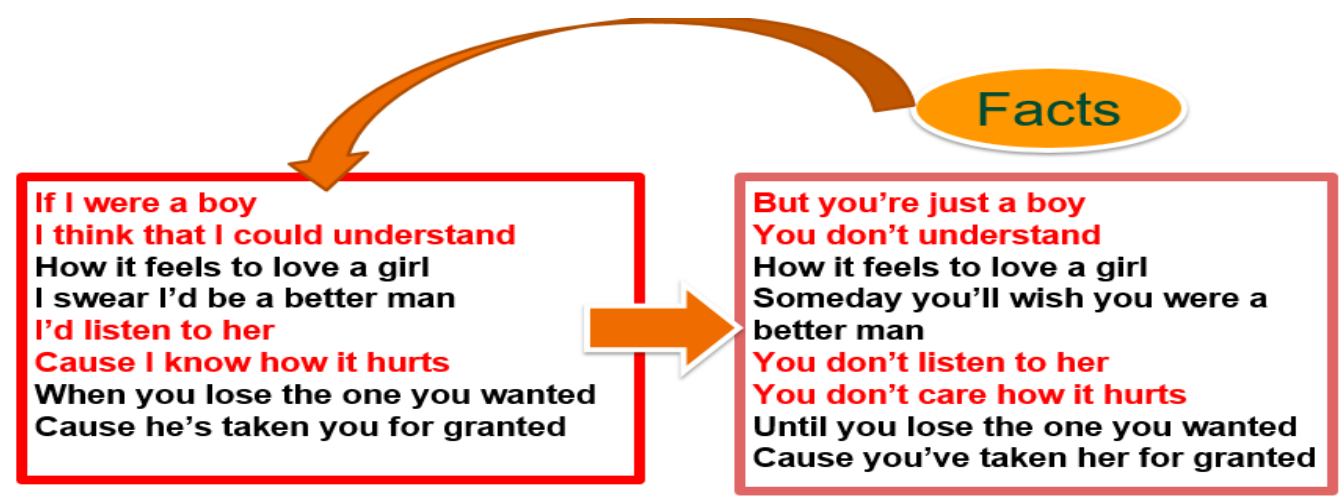

Figure 1. Lyrics presentation

Step 5. Teachers and student can confirm the answer together that the grammar structure shows the possibility.

Step 6. Move forward and present the following two sentences to let learns deduce the differences between the first conditional and second conditional.

If I get an A in TESOL text, I'll...

If I got an A in TESOL test, I'd...

In this case, learners can know well about the difference that the first sentence shows the implying meaning that 'I think it is possible', while the second sentence has the implying meaning that 'but I do not think it will happen'. Meanwhile, they can deal with the grammar point second conditional and sentence structure well.

\section{Conclusions}

There are a series of dilemmas and disputes as for grammar teaching theories and their pedagogical practices. In fact, each method has its advantages and disadvantages, and there is no nostrum for all. There is no right or wrong for grammar teaching concepts or teaching methods. Grammar teaching can draw on strengths of various teaching approaches and methods, among which, consciousness-raising on grammar is necessary. With consideration of current teaching situations such as learning motivation, and teaching aims and requirements, consciousness-raising grammar teaching, together with other teaching approaches, can be integrated and applied to the practical foreign language teaching. Consciousness-raising grammar teaching approach is not static or rigid and can be adjusted in accordance with specific teaching and learning goals and motivation.

\section{Acknowledgements}

This paper is sponsored by Teaching Reform Project of Shandong Technology and Business University (No. 11688JXYJ2015009) and 2016 Blended Learning Teaching Curriculum Reform Project of Shandong Technology and Business University. 


\section{References}

[1] A. Fortune, Self-study grammar practice: Learners views and preferences, ELT Journal, 46 (1992), pp. 160-171.

[2] A. O. Hadley, On learning a language: some theoretical perspectives, Teaching Language in Context, 2nd edition, Heinle \& Heinle, Boston, 1993, pp. 46-47.

[3] D. Willis, J. Willis, Consciousness-raising activities, in: D. Willis, and J. Willis, (eds.) Challenge and Change in Language Teaching, Macmillan Heinemann, Oxford, 1996, pp. 63-76.

[4] H. D. Brown, Principles of Language Learning and Teaching, Prentice Hall Regents, New Jersey, 1994.

[5] J. L. Shrum, \& W. G. Eileen, Teachers Handbook: Contextualized Language Instruction. 4th edition, Heinle \& Heinle, Boston, 2010.

[6] J. Truscott, The case against grammar correction in L2 writing classes, Language Learning, 46 (1996), pp. 327-369.

[7] J. Truscott, Noticing in second language acquisition: a critical review, Second Language Research, 14 (1998), pp. 103-135.

[8] K. Glaser, News from the pragmatics classroom: Contrasting the inductive and deductive approach in the teaching of pragmatic competence, Intercultural Pragmatics, 13 (2016), pp. 529-561.

[9] M. H. Long, Instructed interlanguage development, Issues in Second Language Acquisition: Multiple Perspectives, MA: Newbury House, Rowley, 1988, pp. 115-141.

[10] M. H. Long, Focus on forms in task-based language teaching, in: R. D. Lambert, and E. Shohamy, (eds.) Language Policy and Pedagogy, John Benjamins Publishing Company, Amsterdam, 1998, pp. 179-192.

[11]Q. R. Heng, Review of latest development of grammar teaching researches for FLT, Foreign Language World, 6 (2007), pp. 25-34.

[12]R. DeKeyser, Beyond focus on form: cognitive perspectives on learning and practicing second language grammar, Focus on Form in Classroom Second Language Acquisition. Cambridge University Press, Cambridge, 1998, pp. 42-63.

[13] R. Ellis, Grammar teaching - practice or consciousness-raising, in: J. Richard and W. Rennandya (Eds.), Methodology in Language Teaching: An Anthology of Current Practice, Cambridge University Press, Cambridge, 2002, pp. $167-174$.

[14] R. Ellis, Principles of instructed language learning. System. [online] 2005, Vol. (33), pp. 209-224. Available: http://www.elsevier.com/locate/system [Accessed: 25 December 2016].

[15]R. Ellis, Current issues in the Teaching of Grammar: an SLA Perspective, TESOL Quarterly, 40 (2006), 83-107.

[16]R. Erlam, The effects of deductive and inductive instruction on the acquisition of direct object pronouns in French as a second language. The Modern Language Journal, 87 (2003), pp. 242-260.

[17] R. W. Schmidt, Awareness and second language acquisition, Annual Review of Applied Linguistics, 13 (1993), pp. 206-226.

[18] S. D. Krashen, Explorations in Language Acquisition and Use: The Taipei Lectures, Heinemann, Portsmouth, 2003.

[19] R. Felder, E. Henriques, Learning and teaching styles in foreign and second language education. Foreign Language Annals, 28 (1995), pp. 21-31. 
[20] W. E. Rutherford, M. Sharwood-Smith, Grammar and Second Language Teaching, Newbury House, New York, 1988.

[21]Z. J. Lin, L. Jia, A probe into English grammar teaching innovation, Foreign Language Leaning and Teaching Practice, 3 (2015), pp. 57-62. 